УАK $323(470+571)$

ББК 66.3(2Poc)

DOI 10.22394/1682-2358-2018-5-46-55

N.V. Bututsova, Doctor of Sciences (Law), Professor of the Constitutional and Municipal Law Department, Voronezh State University

\section{CONSTRUCTIVE \\ POLITICAL \\ PARTICIPATION \\ AND IMPROVING \\ THE EFFICIENCY \\ OF PUBLIC AUTHORITY IN RUSSIA}

The article defines the characteristic features of constructive political participation of citizens, including the presence of feedback between citizens and public authorities as an indispensable condition for effective government. The proposals of the author are aimed at increasing the efficiency of political participation of citizens as a necessary condition for the effectiveness of public authority.

Key words and word-combinations constructive political participation, effective public authority and governance, principles and objective laws of governance.
H.В. Бутусова, доктор юридиеских наук, профессор кафедри конституиионного и муниципального праља Воронежского государственноzо унußерсuтета (email: nataliabutusova@mail.ru)

\section{КОНСТРУКТИВНОЕ ПОАИТИЧЕСКОЕ УЧАСТИЕ И ПОВЫШЕНИЕ ЭФФЕКТИВНОСТИ ПУБАИЧНОЙ В ААСТИ в РОССИИ}

Аннотация. Определяются характерные черты конструктивного политического участия граждан, в числе которых наличие обратных связей между гражданами и органами публичной власти как обязательное условие эффективности управления. Предложения автора направлены на повышение политического участия граждан в качестве необходимого условия эффективности публичной власти.

Ключевые слова и словосочетания: конструктивное политическое участие, эффективная публичная власть и управление, принципы и объективные закономерности управления.

B

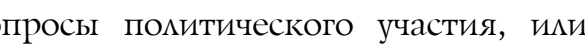
участия гражАан в управлении Аемами государства и общества, всегда были в центре внимания преАставителей правовой и политической науки, социологии, а также теории (науки) социального управления, в рамках которой рассматривается наиболее полное, всестороннее участие граждан в управлении как необходимое условие его эффективности. 
Проблема конструктивности политического участия актуализировалась сравнительно недавно. Это прежде всего связано с событиями последних десятилетий, когда в ряде стран в результате так называемых «цветных революџий» или государственных переворотов, неконституционных действий, подАержанных частью населения, когда к власти пришии политические силы, использовавшие справедиивое недовольство народа прежкней властью, но которые своей политикой быстро развеивают у народа «эйфорию народоправства». Сохраняющаяся сегодня в некоторых регионах чрезвычайная напряженность, опасность эскалации военных конфликтов, представцяющих угрозу миру на планете - результат действия многих факторов, в том числе и политического участия гражАан, которое едва $\Lambda$ можно признать конструктивным. Вместе с тем на примере подобных событий очевидно: если государство не выполняет Аолжным образом свое предназначение по отношению к человеку и его правам как главный субъект их гарантирования, это подрывает саму государственность (понимаемую как систему общественных отношений, складывающихся в связи и в процессе послеАовательной реализации государством своих функций, своего соџиального назначения), но, с Аругой стороны, разрушение государственности «ударяет» по правам и свободам человека и гражданина, резко ослабцяя ици вообще уничтожая систему их гарантирования, а следовательно, и основу Аля конструктивного взаимодействия государства и гражданского общества.

Извлекая уроки из прошлого Аля того, чтобы не Аопустить разрушения государственности и обеспечить устойчивое развития общества и государства, необходимо создать надежную систему защиты прав человека и повысить эффективность пубцичной власти в России. В связи с этим всестороннее исслеАование значения, характерных черт и условий конструктивного политического участия представцяет не только теоретический, но и практический интерес.

В Толковом словаре С.И. Ожегова значение слова «конструктивный» опредемяется как такой, что можнно положить в основу чего-то, как плодотворный [1] . В Словаре русских синонимов в качестве синонимов слова «конструктивный» называются: полезный, умный, применимый, разумный, плодотворный, Аемьный, Аеловитый, путный, деловой, путевый [2]. Как справедливо отмечается в научной митературе, конструктивность взаимодействия субъектов общественных отношений зависит от поведения каждого из них, от их готовности пубцично вести диалог, выстраивать партнерские отношения [3, с. 6] .

Термин «политическое участие» в большей мере востребован политической наукой, где существует немало определений этого понятия [4], но все они основаны на том, что политическое участие преАставцяет собой разновидность политической деятельности граждан, цель которой - воздействие на принятие и осуществление политических решений. В политической науке изучены мотивы и модели политического участия, его формы. Среди форм политического участия, классифицируемым по разным основаниям, в частности выделяют мегальные (участие, разрешенное законом) и нелегальные (запрешенные законом формы политической деятельности - например, терроризм или не разрешенные властями акции протеста); индивидуальные и комлективные; 
постоянные и эпизодические; традиционные и инновационные; участие на местном, регионацьном или федеральном уровне и Аругие.

В правовой науке термин «политическое участие», как правицо, не используется. В соответствии с российской Конституцией в качестве основных субъектов политической деятельности выступают российский нароА в целом, отдельные граждане, группы граждан и их объединения (в том числе политические партии), а также органы государственной вмасти и органы местного самоуправления, их должностные миџа. Статья 32 Конституџии РФ закрепляет право граждан «участвовать в управлении делами государства» непосредственно и через своих представителей и его основную форму: избирать и быть избранным в органы пубцичной вмасти [5]. Аанное конституџионное право гражАан является основным в группе политических прав и свобод: Аругие помитические права дополняют и Аетализируют его - право на свободу мысли и слова, свободу информации, право на объединение, право на мирные собрания, митинги, Аемонстрации, шествия и пикетирования; право на обращение в органы пубцичной власти (ст. 29-31, 33).

Названные конституционные нормы определяют возможкные формы участия граждан в политической деятельности, дополняемые п. 6. ст. 2 Федерального закона от 12 января 1996 г. № 7-Ф3 (в реА. от 19 декабря 2016 г.) «О некоммерческих организациях» [6], закрепляющего формы осуществления политической деятельности. Хотя указанная норма посвящена политической Аеятельности некоммерческих организаций, за исключением политических партий, эти положения Закона в полной мере применимы и к Аругим субъектам политической активности, вкиючая гражАан.

Помимо перечисления форм политической деятельности в п. 6. ст. 2 названного Федерального закона закрепляется положение о том, что «некоммерческая организация, за исключением политической партии, признается участвующей в политической Аеятельности, осуществляемой на территории Российской Федерации, если независимо от целей и задач, указанных в ее учредительных документах, она осуществляет деятельность в сфере... защиты основ конституционного строя Российской ФеАераџии, обеспечения законности, правопорядка, государственной и общественной безопасности, соџиально-экономического развития Российской Федерации, развития политической системы, деятельности государственных органов, органов местного самоуправления. Таким образом, формально юридически в России не заниматься политической деятельностью (или оказаться вне политического участия) невозможно не только некоммерческим объединениям, но и соџиально активным гражканам.

Теория (наука) соџиального управления опредемяет обязательное привлечение широких слоев народных масс (граждан, работников предприятий и Ар.) к управлению в качестве важнейшего принципа (объективной закономерности) управления. В соответствии с Аанной объективной закономерностью эффективность функщионирования цюбой соџиацьной системы (будь то государство, общество или отдельная организаџия, предприятие) во многом определяется степенью массовости участия разцичных слоев населения в управлении. Речь 
идет главным образом о конструктивном политическом участии: о прямой или опосредованной вовлеченности граждан и их объединений в политиковластные отношения, их участии в формировании органов власти и управления, политических институтов и в выработке политических решений, в правотворческой деятельности.

ОАнако данная закономерность управления давно и успешно используется и в неполитической деятельности - в процессе участия рядовых работников, сотрудников в управлении преАприятиями, учреждениями, организаџиями. Вспомним в качестве фактора резкого повышения производительности и качества труда положительный советский опыт соџиалистического соревнования, или активное привлечение работников к управлению преАприятием как основу японского менеджмента, или внедрение в 1970-х годах на ряде западных фирм систем «промышленной демократии» (т.е. программ, предусматривающих различные формы участия рабочих в управлении преАприятием) $[7$, c. $200-221]$.

Учет в практической управленческой деятельности требований закономерности обязательного привлечения широких слоев населения к управлению является важнейшим показателем демократизма культуры управления. Этот вывод справедиив и дия политического, и дия неполитического участия. СлеАует отметить, что степень реального демократизма государственно организованного общества, выступающего в качестве внешней среды дия различных организаций (предприятий, учреждений), в нем функционирующих, во многом определяет и возможность развития промышленной (производственной) демократии.

Наиболее полно общественно-политический смысл закономерности обязательного привлечения широких народных масс к управлению отражает концепџия народного суверенитета, получившая в XX в. во всех демократических государствах конституционное закрепление. Принцип суверенитета народа в конституциях демократических государств закрепляется как основа демократического устройства общества и государства. В действительности же принцип суверенитета народа (народовцастия) явцяется скорее конституционным идеацом, чем достигнутым состоянием: на протяжении всей истории развития человечества народ бым отчужден, удацен от власти, выступац преимущественно в роли объекта, а не субъекта властвования. Этот вывод справедцив не только дия России, но и Аля государств, чья демократическая природа никогда не ставилась под сомнение. Не случайно большинство современных концепций Аемократии обходят проблему народа, являющуюся исходной Амя всякой теории демократии, а политические системы, называющие себя демократическими, постепенно вырабатывают у себя способность обходиться без народа, таким образом «в двадцатом веке теория и практика демократии теряет свою Аушу» [8, с. 142] . Абсолютно правы авторы, которые считают, что нельзя ставить под сомнение естественно-правовой характер народовцастия, суверенитета нароАа, отказываться от этой идеи по причине несоответствия нормативной основы народовластия реалиям жиини.

Объективная закономерность максимацьно широкого привлечения граж- 
Аан к управлению, получившая конституционное закрепление как принцип суверенитета народа, как раз и отражает объективную потребность в реацьном народовцастии, в укрепцении его гарантий как необходимого условия наиболее полной реацизации прав человека и обеспечения конструктивности политического участия Аця эффективного управления обществом и госуАарством.

Эффективность управления с позиџии кибернетики - науки «об общих закономерностях управления в природе, в человеческом обществе, в технике» [9, с. 21-22], предполагает получение максимального эффекта при минимальных усилиях и затратах. При этом, безусловно, имеет свою специфику содержание понятия эффективности публичного управления как разновиАности социального управления, преАставцяющего собой целенаправленное, упорядочивающее воздействие субъектов, обладающих публичной властью, на объект управления в цемях достижения каких-либо общественно значимых резуиьтатов.

Во-первых, в современный период важнейшим условием успешного, эффективного функционирования и развития июбого общества, государства и человеческой цивилизации в целом является повышение роли науки в процессе управления, и особенно в принятии стратегических управленческих решений. Именно поэтому эффективным можкет быть только научно обоснованное пубцичное управление. Теория соџиального управления - наука, изучающая гамму многообразных аспектов управленческой деятельности, важнейшие из которых ее объективные закономерности, сущность, структура, Аинамика, управленческая этика, эстетика, психология, культура управления. При определении эффективности мюбого управленческого решения необходимо руководствоваться выводами размичных наук, и в первую очередь принџипами и объективными закономерностями науки управления. Во-вторых, анализ эффективности деятельности органов пубцичной власти предполагает ее оџенку с точки зрения соответствия Конституции РФ и законам. Следовательно, эффективным может быть только научно обоснованное и конституционное, базирующееся на требованиях законов публичное управление. Названные усмовия эффективности публичной вмасти имеют решающее значение и Аля обеспечения конструктивности политического участия.

Итак, конструктивность взаимоотношений государства, органов пубцичной власти и гражданина, гражданского общества прежде всего зависит от научной обоснованности их позиций. Например, по мнению ученых, в настояшее время человечество находится на пороге глобальной экологической катастрофы, так как интенсивность негативного антропогенного воздействия на биосферу уже превысила все Аопустимые пределы. Вследствие этого сырьевое развитие в XXI столетии бесперспективно не только с социально- экономической, но и с экологической точки зрения. В связи с этим Аюбое решение о добыче каких-либо полезных ископаемых должно приниматься органами вцасти только после тщательной и всесторонней экологической экспертизы с участием ученых и общественности. Это позволит минимизировать экологический вред от вторжения в экосистемы и не Аопустить такие разработки 
полезных ископаемых, которые с большой Аолей вероятности могут привести к экологической катастрофе. Как субъект межАународного права Россия с ее огромной территорией и богатыми природными ресурсами ответственна за их разумное и экологически безопасное использование не только перед собственным народом, но и перед мировым сообществом, перед настоящими и буАущими поколениями.

В связи с этим гражданское общество призвано осуществцять контроль за тем, в коей мере деятельность государства, органов пубцичной власти и их

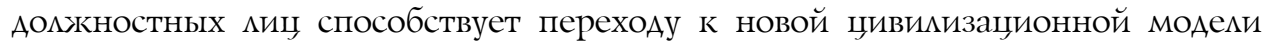
устойчивого разбития - научно обоснованного развития в гармонии с природой и на основе общечеловеческих ценностей, а назначение и обязанность современного государства - создать Аля этого все необходимые условия. Такое взаимодействие (при условии, что оно осуществляется в рамках закона), безусловно, Аолжно быть названо конструктивным.

ИзАоженное в полной мере соответствует идеям опубцикованного в декабре 2017 г. юбилейного докмада Римского клуба, остающегося основной научной площадкой в мире, в рамках которой формируется повестка ответственного глобализма и устойчивого развития. В этом докладе («Come on! Capitalism, Short-termism, Population and the Destruction of the Planet» - "Aaßайme же! Капитализм, близорукость, население и разрушение планеть»), широко обсуждавшемся на Западе и не отмеченном пока должным вниманием в России, обосновывается новый вектор мирового развития в целях построения еАиной планетарной гармоничной цивимизации [10 ] .

С точки зрения конституционно-правового подхода Аюбая конструктивная Аеяте ьность Аолжна осушествляться Аля Аостижения конститущионно закрепменных цемей и конституџионными среАствами. Применительно к содержанию взаимоотношений граждан, их объединений с органами государственной власти и местного самоуправления следует подчеркнуть приоритетную необходимость их конституџионности: Конституция РФ определяет важнейшие ценности - человек, его права и свобод, демократия, правовое государство, закрепляет их иерархию (человек, его права, свободы - высшая ценность), устанавливает взаимные права и обязанности государства и кичности в сфере индивиАуальной свободы и частной жизни, в сфере реацизации политической свободы индивида, в сфере защиты насущных материальных и духовных потребностей человека. Законодательное регулирование позволяет определить допустимые формы и процедуры реализации взаимных прав и обязанностей названных субъектов правового общения. Аیя правового состояния российского гражданства характерны отношения социального партнерства при решении общественно значимых вопросов и проблем. Стороны правового общения (государство и гражданин) должны стараться находить согласованные решения на основе гармонизации законных интересов и с учетом их иерархии, опредеменной Конституцией, где высшая ценность - человек, его права и свободы, а обязанность государства - их признавать, соблюдать и защищать (ст. 2).

К важнейшим условиям конструктивного взаимодействия гражданского общества, в частности общественных объединений, и государства, его органов, 
Аолжностных мищ по общественно значимым вопросам следует отнести способность и готовность обеих сторон к конструктивному Аиалогу, основанному на взаимном уважении, умении и желании слушать и слышать Аруг Аруга. Следовательно, конструктивное политическое участие граждан и их общественных объединений Аолжно Аополняться конструктивной Аеятельностью органов государственной власти и местного самоуправления.

В соответствии с кибернетическим принщипом (закономерностью) обратных связей органы государственной власти и местного самоуправления (управляющая система), принимающие управленческие решения, Аолжны быть информированы о результатах своего воздействия, внимательно изучать, анамизировать всю необходимую информацию, поступающую от гражданского общества, связанную с реацизацией принятого решения, вовремя устранять ошибки, Аопущенные, в том числе, и в связи с принятием конкретного решения, при необходимости корректировать свое управленческое воздействие, то есть обеспечивать перестройку системы. Аксиомой науки и практики управления явцяется вывоА о том, что при отсутствии обратных связей проџесс управления становится невозможным, а игнорирование указанной закономерности приводит к серьезным сбоям в функционировании системы и даже к ее разрушению. Печальными подтверждениями правильности этого вывода могут служить целые этапы современной истории России (периоды застоя, перестройки, радикальных экономических реформ), а также похожие процессы в других государствах, в частности на постсоветском пространстве.

К сожалению, можно привести неединичные примеры неконституционной и неконструктивной деятельности политических элит, органов пубцичной власти в России «в михие Аевяностые». Аостаточно вспомнить историю разрушения Советского Союза, когда фактически и союзная и российская вцаствующие элиты проигнорироваци волю многонаџионацьного многомицмионного советского народа, выражкенную на союзном референдуме 17 марта 1991 г.: тогда более 75\% от общей списочной численности избирателей на референдуме проголосовали за сохранение Союза (в России за сохранению Союза высказалось чуть больше 71\%), несмотря на это, инициированные политическим руководством России неконституџионные действия, направленные на окончательное разрушение Союза, завершились денонсацией Аоговора об образовании СССР Верховным Советом РСФСР. В Послании Фелеральному Собранию РФ 2005 г. Президента В.В. Путина «крушение Советского Союза» было названо «крупнейшей геополитической катастрофой века» [11], а в интервью французским СМИ в 2014 г. - «одной из самых крупных гуманитарных катастроф XX века» [12] ; продолжающиеся кровавые события на Украине могут служить печальным подтверждением правицьности данного вывода. Подчеркнем, что «катастрофа» эта была рукотворной - в решающей степени следствием неконституционных и неконструктивных Аействий союзной и российской вцаствующих элит.

К сожацению, не толыко в «лихие девяностые», но и сегодня существуют серьезные проблемы, свидетельствующие о том, что органы пубцичной власти не всегда готовы к конструктивному взаимодействию с гражданским обще- 
ством, отдельными гражданами. Серьезное беспокойство вызывает недооценка Российским государством роли общественных объединений в современном мире. Именно общественные объединения способны выполнять функцию канала связи гражданского общества, народа и государства. ОАнако по срав-

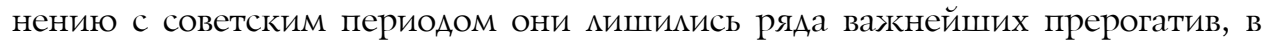
частности права законодательной инициативы, остается также нереализованным огромный потенциал общественных объединений по осуществлению этического контроля на стадии разработки управленческих решений, разцичных нормативных актов, а законодательство об иностранных агентах [13] действует разрушающе по отношению не только к общественным объединениям, сотни которых по стране уже прекратили свое существование, но и к гражданскому обществу, важнейшие элементы которого представлены общественными объединениями [14, с. 13-15]. Государству необходимо учиться выстраивать партнерские отношения не только с благотворительными общественными объединениями и иными общественными формированиями, созданными по инициативе или (и) при участии органов государственной власти (Общероссийский народный фронт, общественные палаты, общественные советы и Ар.), но и с независимыми, «автономными» некоммерческими объединениями граждан, в том числе и оппозищионно настроенными по отношению к Аействующей власти. Это в полной мере соответствует требованиям объективной закономерности обязательного привлечения широких народных масс к управлению делами государства, конституционному принципу народного суверенитета.

Важными каналами обратной связи между государством и народом, гражАанским обществом, каждым гражданином являются публичные мероприятия, обращения граждан в органы государственной вмасти и местного самоуправления. В Аокмаде о деятельности Уполномоченного по правам человека в Российской Федерации за 2017 г. обращается внимание на факты незаконного преследования граждан за критику деятельности органов государственной

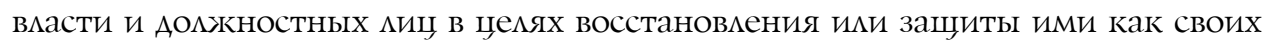
прав и свобод, так и прав и свобод Аругих миџ; на размытость получаемых гражданами ответов на свои жалобы, на ответы не по существу обозначенных проблем; на забюрократизированность процедуры согласования проведения пубцичных мероприятий, на необоснованные отказы в согласовании проведения мирных собраний и демонстраций, незаконные привлечения к аАминистративной ответственности за организаџию или участие в публичных мероприятиях [15].

По мнению российского омбудсмена, в демократическом государстве приобретает большое значение не только обеспечение реализации гражданами права на проведение пубцичных мероприятий и участие в них, но также гарантии того, что их позиџия будет услышана и учтена. В связи с этим важно, чтобы органы власти и управления воспринимали сигналы и своевременно реагироваци на них в рамках своей компетенџии.

С неэффективностью Аеятельности органов пубцичной вцасти по обеспечению прав, свобод, законных интересов граждан нередко связан уровень протестной активности в обществе [16]. В частности, экологические обще- 
ственные объединения поддерживают протестные акщии Аруг Аруга, направменные на противодействие безответственным намерениям офиџиальных властей реацизовать проекты строительства промышленных объектов, начать разработку полезных ископаемых, способную причинить серьезный, нереАко

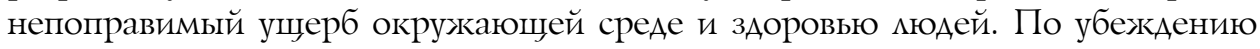
российского омбудсмена, «снижению протестных настроений способствуют не репрессивные меры, а своевременное решение проблем, волнующих население и побуждающих участвовать в публичных мероприятиях. В связи с этим большое значение имеет «непрерывный конструктивный диалог межАу обществом и вмастью» [15, с. 7].

К сожалению, органы государственной вмасти и местного самоуправления нередко демонстрируют нежелание и неумение вести конструктивный диалог с народом, представителями гражданского общества, что известно автору статьи как участнику экологического общественного Авижения по собственному опыту [17]. По-видимому, при таком отношении вцастных структур к вполне обоснованной озабоченности граждан устраняется сама основа Аця их конструктивного взаимодействия. Ведь речь идет Ааже не о «высоких стандартах экологического благополучия», не о «качестве жкизни», что отмечал В.В. Путин в Послании Федерацьному Собранию РФ от 1 марта 2018 г. [18], а о необходимых гарантиях конституционного права на жкизнь человека как высшей ценности и об обязанностях государства это право признавать, собцюдать и защищать (ст. 2) и в конечном итоге - об обеспечении национальной безопасности страны.

Конструктивное политическое участие способно противодействовать коррупции, позитивно влиять на содержание стратегических управленческих решений и с точки зрения уровня их научной обоснованности, и последовательного отражения в них интересов народа, обеспечивать активное вкмючение гражданского общества в решение задач по переходу к устойчивому развитию общества и государства. Объективная потребность в конструктивном взаимодействии гражданского общества и органов пубцичной власти в России требует корректировки вектора политического развития страны в последние Аесятицетия, которое пока носит преимущественно элитарный характер: вцаствующей элитой пока не создаются необходимые условия Аля широкого Аейственного участия в нем народа и гражданского общества, то есть условия Аля конструктивного политического участия. Разумеется, эта ситуация нуждается в скорейшем исправлении.

\section{Библиографический список}

1. Ожегов С.И. Словарь русского языка / под общ. ред. Л.И. Скворцова. 24-е изд., испр. M., 2007.

2. Словарь синонимов русского языка: Практический справочник. URL: http://dic.academic. ru/dic.nsf/ogegova/88010.

3. Риэккинен М.А. Конституционно-правовые основы конструктивного протеста: автореф. дис. ... д-ра юрид. наук. Тюмень, 2017.

4. Политическое участие. URL: http://center-yf.ru/data/stat/politicheskoe-uchastie-eto.php

5. Конституция Российской Федерации. М., 2015. 
6. URL: http://ipipip.ru/zakon-o-nekommercheskih-organizaciyah/2/

7. Кнорринг В.И. Искусство управления: учебник. М., 1997.

8. Ефимов В.И. Система государственной власти: теоретико-организационная основа и политическая динамика: дис. ... д-ра юрид. наук. М., 1994.

9. Берг А.И. Кибернетика, мышление, жизнь. М., 1964.

10. URL: https://batrachos.com/sites/default/files/pictures/Books/Weizsacker_Wijkman_2018_ Come\%20on.pdf

11. Послание Президента РФ Федеральному Собранию Российской Федерации от 25 апр. 2005 г. [Электронный ресурс]. Доступ из СПС «КонсультантПлюс».

12. Интервью В.В. Путина французским СМИ. URL: http://www.fontanka.ru/2014/06/05/064/ big.5.html

13. О внесении изменений в отдельные законодательные акты Российской Федерации в части регулирования деятельности некоммерческих организаций, выполняющих функции иностранного агента: Федер. закон от 20 июля 2012 г. № 121-ФЗ [Электронный ресурс]. Доступ из СПС «Гарант».

14. Butusova N. Constitutional regulation and practical implementation of public control in Russia // Legal, Social and Political Control in National, Intarnational and EU 13-1AW: Collection of papers from the International Scientific Conference. 2016. Nis. Serbia.

15. Доклад о деятельности Уполномоченного по правам человека в Российской Федерации за 2017 г. // Российская газета. 2018. 17 апр.

16. Михайлова E.B., Скогорев А.П. Протесты как форма гражданской активности в современной России // Власть. 2017. № 1. С. 109-117.

17. Бутусова Н.B. Конструктивное политическое участие граждан как гарантия их конституционных прав // Општествените промени во глобалниот свет: книга на апстракти: Четврта мегународна научна конференција. Штип: Универзитет Гоце Делчев, 2017. С. 677-695.

18. Послание Президента РФ Федеральному Собранию РФ от 1 марта 2018 г. [Электронный ресурс]. Доступ из СПС «Гарант». 